\title{
TUBERCULOSE BOVINA EM BACIA LEITEIRA DO ESTADO DE MINAS GERAIS
}

\section{BOVINE TUBERCULOSIS ON DAIRY CATTLE IN MINAS GERAIS STATE}

\author{
M. A. SOUZA $^{1 *}$, F. M. U. OLIVEIRA ${ }^{1}$, L. D. OLIVEIRA ${ }^{1}$, N. G. BOMBONATO ${ }^{1}$, P. M. SOARES ${ }^{1}$,
} A. M. C. LIMA $^{1}$

\section{RESUMO}

A tuberculose bovina, enfermidade causada pelo Mycobacterium bovis, é uma zoonose cujo hospedeiro primário é o bovino. A doença é endêmica em vários países principalmente naqueles em desenvolvimento com rebanhos de criações intensivas, como em bovinos leiteiros, principalmente rebanhos estabulados. $\mathrm{O}$ objetivo deste trabalho foi avaliar a ocorrência da tuberculose em um rebanho bovino pelo teste cervical comparativo (TCC). O estudo foi realizado em um rebanho de exploração leiteira no município de Perdizes MG. A propriedade não participava do Programa Nacional de Controle e Erradicação da Brucelose e Tuberculose (PNCEBT), e tinha histórico de importação de animais de propriedades vizinhas, sem atestado negativo para tuberculose. Realizou-se a tuberculinização em 164 bovinos da raça Girolando, 158 fêmeas e seis machos, com idade aproximada entre seis meses a 14 anos. Para realização do TCC foram utilizados cutímetro Suprivet de pressão e seringas semi-automáticas multidose McLintock. As tuberculinas PPD bovina e aviária foram adquiridas do laboratório TECPAR/PR. Os resultados das diferenças $(\Delta \mathrm{B}-\Delta \mathrm{A})$ foram interpretados de acordo com os critérios definidos na tabela do Regulamento Técnico do PNCEBT, sendo $(\Delta \mathrm{B}-\Delta \mathrm{A}<1.9)$ reação negativa, $(\Delta \mathrm{B}-\Delta \mathrm{A}$ entre 2 a 3,9$)$ reação inconclusiva e $(\Delta \mathrm{B}-\Delta \mathrm{A}>4,0)$ reação positiva. Dos 164 bovinos testados, $41(25 \%)$ foram positivos, $29(17,7 \%)$ inconclusivos e $94(57,3 \%)$ negativos. Dentre os positivos, todas eram fêmeas com idade superior a três anos. Todos os animais reagentes positivos foram encaminhados ao abate sanitário. Após 60 dias de intervalo foi realizado o reteste nos bovinos inconclusivos, e o TCC detectou mais sete vacas positivas, que também foram encaminhadas ao abate sanitário. Conclui-se que este foco de tuberculose bovina representa um risco zoonótico, por isso mesmo recomenda-se a utilização de testes de diagnóstico para o saneamento nas propriedades de exploração leiteira.

PALAVRAS-CHAVE: Mycobacterium bovis. TUBERCULINA. ABATE SANITÁRIO. LEITE.

AGRADECIMENTOS: Á Coordenação de Aperfeiçoamento de Pessoal de Nível Superior pela concessão da bolsa de estudos da autora.

ÁREA TEMÁTICA: Doenças Infecciosas 